\title{
Role of sphingolipids in oestrogen signalling in breast cancer cells: an update
}

\author{
O Sukocheva' and C Wadham ${ }^{2}$ \\ ${ }^{1}$ Division of Surgery, Flinders University of South Australia, Bedford Park, South Australia 5042, Australia \\ ${ }^{2}$ Children's Cancer Institute Australia, University of New South Wales, Sydney, New South Wales, Australia
}

\author{
Correspondence \\ should be addressed \\ to O Sukocheva \\ Email \\ olga.sukocheva@ \\ flinders.edu.au
}

\begin{abstract}
The signaling pathways activated by the steroid hormone oestrogen include a variety of cytoplasmic second messengers linked to a multitude of tissue-specific effects. In the last decade, sphingolipids and their membrane receptors were added to the list of oestrogenactivated mediators. Oestrogen triggers the sphingolipid signalling cascade in various tissues including breast cancer. Extensive research has shown that sphingolipids are the key regulatory molecules in growth factor networks. Sphingolipids can control the rate of cell proliferation and the differentiation outcome during malignant transformation. In this study, we summarise novel experimental evidences linking sphingolipids to oestrogenactivated effects, highlight the role of sphingolipids in cancer cells and discuss new avenues for future research at the intersection between oestrogen and sphingolipid signalling.
\end{abstract}

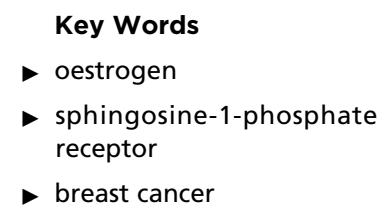

Journal of Endocrinology (2014) 220, R25-R35

\section{Introduction}

Sphingolipids contain a complex family of naturally occurring molecules that are enriched in cellular membranes and serve as a reservoir for the production of bioactive metabolites, including sphingosine, ceramide, sphingosine-1-phosphate (S1P) and ceramide-1-phosphate. The clinical importance of sphingolipid research became evident a decade ago when the analysis of patients' samples demonstrated significantly elevated levels of sphingosine kinase 1 (SPHK1) mRNA expression in a variety of solid tumours (French et al. 2003). However, several years before these important clinical findings, the involvement of sphingolipids in the regulation of cancer cell proliferation, survival and migration was discovered in vitro (Spiegel et al. 1994).

Since then, the role of sphingolipids as carcinogenesisrelated signalling molecules has been extensively investigated in various cancer models (Vadas et al. 2008, Meacham et al. 2009, Furuya et al. 2011, Aoyagi et al.
2012). Sphingolipids, specifically S1P, have been shown to mediate numerous pro-oncogenic processes including evasion of apoptosis (Cuvillier et al. 1996, Goetzl et al. 1999a,b, Xia et al. 1999, Edsall et al. 2001, Limaye et al. 2005), cell transformation (Xia et al. 2000, Pitson et al. 2005, Hsu et al. 2012), uncontrolled proliferation (Shu et al. 2002, Sarkar et al. 2005), desensitisation of antigrowth agents (Sukocheva et al. 2009, Watson et al. 2010, Antoon et al. 2011a,b, Antoon et al. 2012), angiogenesis (Hobson et al. 2001, Nagahashi et al. 2012) and metastasis (Furuya et al. 2011, Aoyagi et al. 2012, Bao et al. 2012). A new cutting-edge discovery demonstrated that in addition to their second messenger functions, sphingolipids can act as cofactors, regulating the function of transmembrane proteins (Contreras et al. 2012). The finding of an unprecedented specificity of interaction of a transmembrane domain with an individual sphingolipid species adds to our understanding of why biological

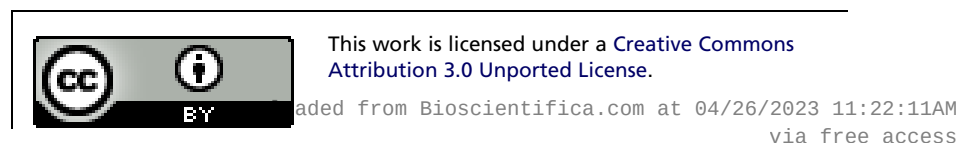


membranes are assembled from such a wide variety of different lipids (Contreras et al. 2012).

Changes in cellular metabolism, associated with active growth and division, are tightly linked to the synthesis of membrane phospholipids and sphingolipids, supplying cells with material to build plasma membrane and various membrane-structured intracellular organelles in growing and dividing cells (Holthuis et al. 2001). Notably, sphingolipid metabolism is activated during normal cell growth and division not only to provide a basic supply of structural and functional metabolites but also to serve as second messengers (Lebman \& Spiegel 2008, Aoyagi et al. 2012). In this review, we analysed recent knowledge gained at the crossroads of sphingolipid and oestrogen signalling pathways in breast cancer cells (BCC).

\section{Sphingolipid signalling in a spotlight of anti-cancer research}

Apoptosis (programmed cell death) is the rational decision of cells to self-eliminate when one and/or more of the essential cell functions are compromised. The capacity for timely apoptosis initiation can serve as a marker of the cell being 'normal'. Conversely, all cancer cells demonstrate inherent abnormalities in apoptosis activation. That is why all anti-cancer drugs aim to reactivate the impaired parts of the apoptotic machinery. A central hypothesis of the role of sphingolipids in the regulation of apoptosis, the rheostat model, was suggested by Spiegel et al. less than two decades ago (Cuvillier et al. 1996). The hypothesis was later confirmed as a key mechanism adopted by various receptor-mediated signalling cascades (Hannun \& Obeid 2008, Meacham et al. 2009, Furuya et al. 2011; Fig. 1). Two principle members of the sphingolipid rheostat, ceramide and sphingosine, have been described as proapoptotic molecules and mediators of apoptosis-related changes as observed, for instance, during cell cycle dysfunction in cancer cells (Hannun \& Obeid 2008). Stress stimuli, such as Fas ligands, oxidative stress, growth factor withdrawal, anti-cancer drugs, ionising radiation, heat shock or ultraviolet light, induce elevated endogenous cellular levels of sphingosine and ceramides to initiate cell cycle arrest and death in various normal and malignant cells (Hannun \& Obeid 2008). However, when phosphorylated by SphK, sphingosine transforms into S1P, another bioactive lipid with anti-apoptotic properties that propogates signals leading to cell growth and proliferation, and counteracts apoptosis (Hannun \& Obeid 2008, Vadas et al. 2008; Fig. 1). Details of sphingolipid metabolism have been recently reviewed (Furuya et al. 2011, Aoyagi et al. 2012).

In the human body, S1P is constitutively produced by the action of SphK1 and SphK2 in erythrocytes and endothelial cells, resulting in high $(\approx 0.5 \mu \mathrm{M})$, steadystate plasma S1P content and a steep S1P concentration gradient within plasma, lymph and tissue interstitial fluid (Hänel et al. 2007). S1P is also produced and released locally by activated platelets and tumour cells and/or by the tumour microenvironment (Takuwa et al. 2011).

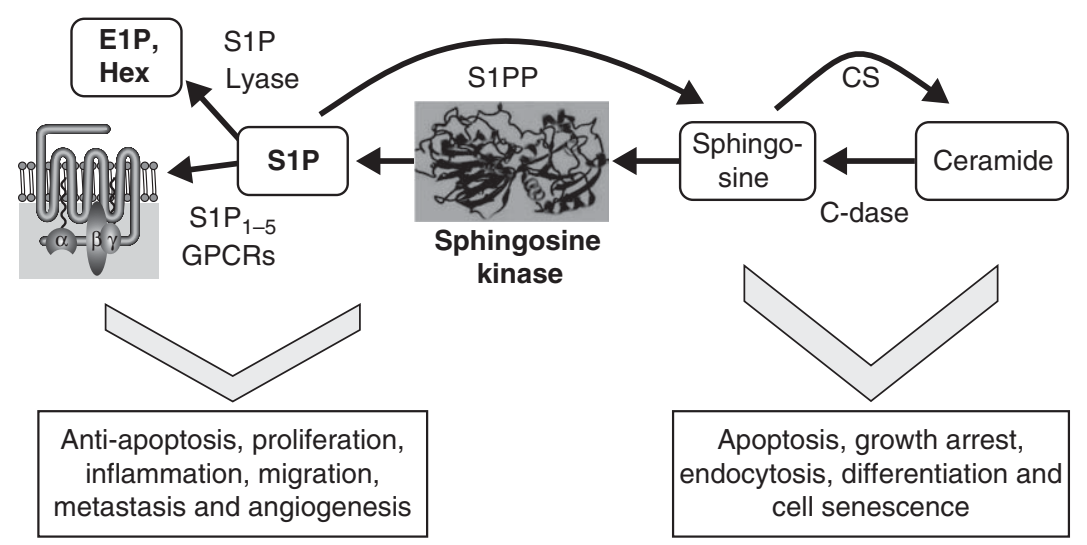

\section{Figure 1}

Sphingolipid rheostat model: balancing between survival and death depends on the ratio of specific sphngolipids. Proapoptotic ceramide can be deacylated by ceramidase to form sphingosine, which in turn can be phosphorylated by SphK to produce the pro-survival molecule S1P. These reactions are reversible and the only exit point from the cycle is the irreversible degradation of S1P to hexadecenal and ethanolamin-1- http://joe.endocrinology-journals.org DOI: 10.1530/JOE-13-0388 (c) 2014 The authors Printed in Great Britain phosphate. S1P can bind to and activate a family of five G-protein-coupled receptors (GPCRs), referred to as $\mathrm{S}_{1 \mathrm{P}_{1-5}}$, to elicit autocrine or paracrine signalling. CS, ceramide synthase; C-dase, ceramidase; S1P, sphingosine1-phosphate; S1PP, S1P phosphatase; E1P, ethanolamine-1-phosphate; Hex, hexadecanal. 
According to the pro-inflammatory model of cancer, immune cells, vascular endothelium, fibroblasts and soluble factors comprise the microenvironment of cancer cells. S1P produced by the vast majority of these cancer-associated cells influences features of malignant transformation and cancer progression. For instance, S1P is strongly chemotactic for endothelial cells (English et al. 1999, Lee et al. 1999) as well as for immune cells (Kveberg et al. 2003, Matloubian et al. 2004) and consequently has been linked to the promotion of angiogenesis and metastasis (Rolin \& Maghazachi 2011, Pyne et al. 2012).

A variety of cells can sense the level of S1P in blood and lymph using plasma membrane $\mathrm{S} 1 \mathrm{P} n$ (where $n=1-5$ ) receptors. S1P receptors are differentially coupled to heterotrimeric G-proteins, which can initiate a multitude of downstream signalling cascades (Alvarez et al. 2007). $\mathrm{S}_{1} \mathrm{P}_{1}, \mathrm{~S}_{1} \mathrm{P}_{2}$ and $\mathrm{S}_{1} \mathrm{P}_{3}$ are widely expressed and considered to be crucial regulators of cancer cell growth and survival due to their ability to switch on important intracellular enzymes such as Ras/extracellular signal-regulated kinase (Erk) and PI3K/Akt and their pathways (Rosen \& Goetzl 2005).

The role of S1P and S1P receptors has been extensively researched in cancer cells. It was shown that production of S1P is stimulated by several growth factors during activation of proliferation (Lebman \& Spiegel 2008, Vadas et al. 2008). Clinical data confirmed the importance of sphingolipid signalling in human breast carcinomas (Ruckhäberle et al. 2008, Watson et al. 2010, Pyne et al. 2012). Accordingly, monitoring the expression levels of SphK1 and S1P receptors has been suggested as a clinical tool for improving diagnosis and prognosis of breast cancer (Ruckhäberle et al. 2008, Watson et al. 2010, Pyne et al. 2012).

\section{S1P is a messenger to enhance proliferation and survival}

S1P is produced by two isoforms of a highly conserved cytoplasmic enzyme SphK (SphK1 and SphK2) that catalyse the phosphorylation of sphingosine (Cuvillier et al. 1996; Fig. 1). Generated from two distinct genes, human Sphk1 and SphK2 vary considerably in size, because SphK2 is almost twice longer than SphK1 (Neubauer \& Pitson 2013). Although both SphK1 and SphK2 can be found in cytoplasm where the enzymes catalyse sphingosine to produce intracellular S1P, these two isoforms differ in substrate binding pockets (Gao et al. 2012, Neubauer \& Pitson 2013), can translocate to different intracellular compartments and appear to possess distinct biological functions (Spiegel \& Milstien 2007, Aoyagi et al. 2012). For instance, SphK1 is a potent anti-apoptotic and growth-promoting signalling enzyme, whereas SphK2 has been shown to initiate proapoptotic cascades (Liu et al. 2003, Neubauer \& Pitson 2013). The specific signalling roles of SphK1 and SphK2 are probably related to their subcellular localisation after activation (Pitson et al. 2005). In particular, the phosphorylation-dependent translocation of SphK1 from the cytoplasm to the plasma membrane is required for its oncogenic activity (Pitson et al. 2005). SphK1, but not SphK2, was found to be responsible for increased export of S1P from BCC (Takabe et al. 2010). Erk1/2 phosphorylates both SphK1 and SphK2 (Pitson et al. 2003, Hait et al. 2009). However, phosphorylation leads to different levels of activation of these two isoenzymes (Pitson et al. 2003). Alternative mechanisms of SphK isoenzyme activation may occur in addition to phosphorylation (Leclercq et al. 2008). More recently, mitochondrial localisation of SphK2 was shown to contribute to mitochondrial membrane permeabilisation and apoptosis (Chipuk et al. 2012). Another recent study also demonstrated that nuclear S1P produced primarily by SphK2 is most likely to contribute to cell cycle arrest (Hait et al. 2009), indicating a potential role of SphK2 in epigenetic regulation (Neubauer \& Pitson 2013).

To date, only SphK1 has been shown to mediate signal transduction from growth and survival-related agents in cancer cells (Pyne et al. 2012). Activation of growth and proliferation results in SphK1 phosphorylation, which, in turn, might enhance Ras-dependent transformation of cancer cells (Xia et al. 2000). Interestingly, in spite of such a close involvement of SphK1 in the regulation of cancer cell growth, there is so far no evidence of mutations occurring in the SPHK1 gene that are linked to cancer, and therefore in strict terms SPHK1 cannot be defined as an 'oncogene'. The term 'non-oncogene addiction' has been used to describe the role of SphK1 in cancer progression (Vadas et al. 2008).

The list of growth factors that rely on S1P as a signalling mediator in a variety of tissues is growing and to date includes platelet-derived growth factor (Hobson et al. 2001), vascular endothelial growth factor (VEGF; Shu et al. 2002), epidermal growth factor (EGF; Auge et al. 2002, Sukocheva et al. 2006) and insulin-like growth factor (IGF; El-Shewy et al. 2006). There is strong evidence demonstrating that SphK1 has an important growth-regulatory role in BCC (Doll et al. 2007, Rosen \& Goetzl 2005, Sukocheva et al. 2006). Other authors

Published by Bioscientifica Ltd 
(Doll et al. 2007) and we (Sukocheva et al. 2003) have demonstrated that in BCC the proliferation-stimulating steroid hormone oestrogen activates the SphK1 (Fig. 2).

Oestrogen stimulates SphK1 activity in a twofold manner, provoking firstly a rapid and transient effect and then a delayed but prolonged activation. The rapid activation of SphK1 induced by oestrogen is apparently mediated by membrane-associated oestrogen receptors (ERs) coupled to Gi proteins, whereas the delayed action relies on transcriptional activation of nuclear ER. Oestrogen-induced SphK1 consequently activates downstream non-genomic signalling cascades, including intracellular calcium mobilisation and phosphorylation of ERK1/2. Importantly, this cytoplasmic signal transduction pathway is critically involved in the oestrogen-dependent mitogenic and oncogenic action in the human BCCs, because inhibition of this pathway resulted in cell growth arrest (Nava et al. 2002, Sukocheva et al. 2003).

Prolonged activation of SphK1 by oestrogen is associated with ER-regulated genomic signalling and might indicate induction of the SPHK1 promoter via engagement of the oestrogen response element (Doll et al. 2007). Several potential transcription factor binding sites have been identified in the SPHK promoter region, including Sp1, AP1, AP2, AP4 and STAT (Nakade et al. 2003, Sobue et al. 2005). However, which transcription factors account for the SPHK gene regulation by ER remains to be identified.

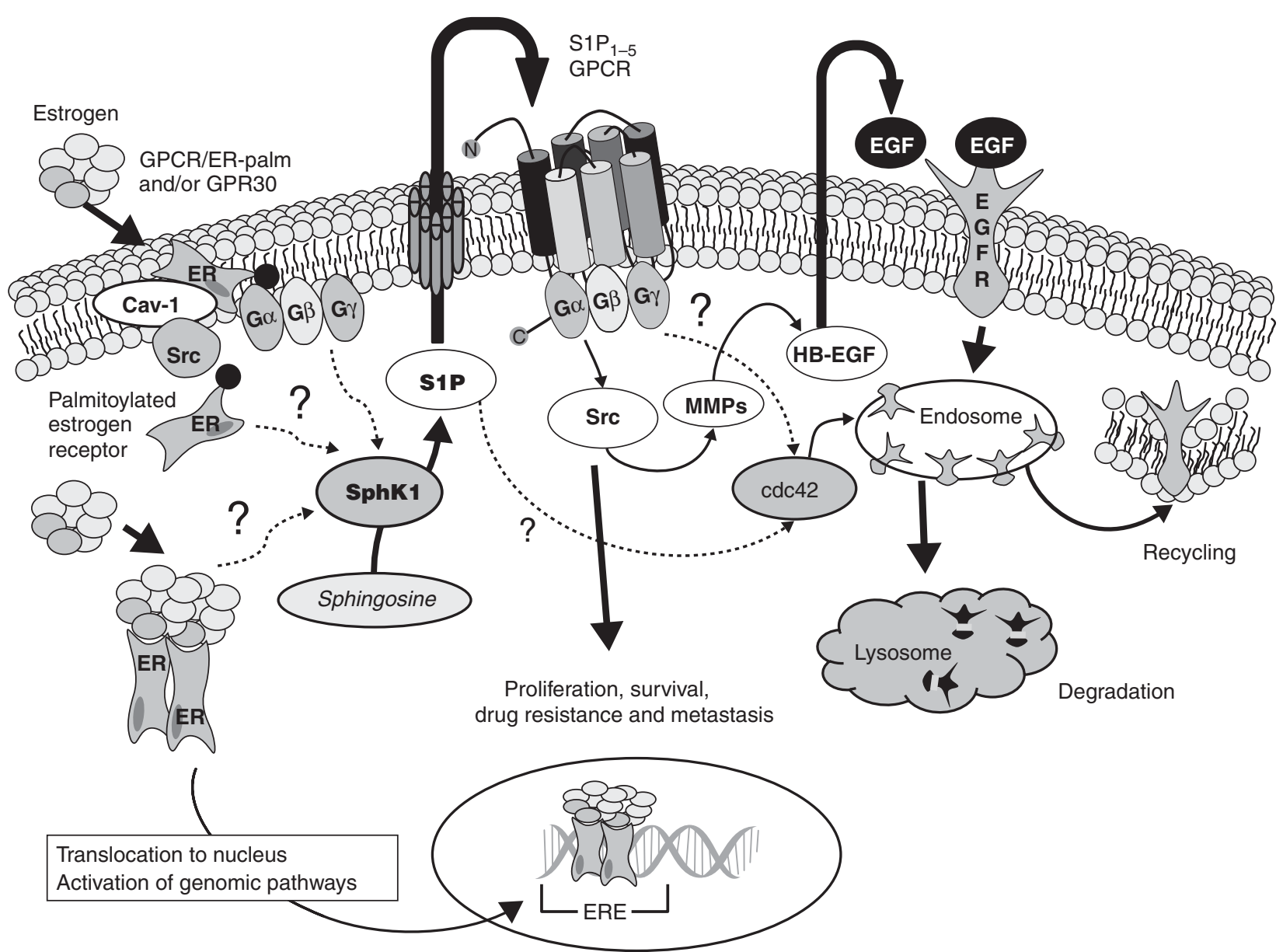

Figure 2

Hypothetical place of SphK1/S1P receptors in oestrogen and EGFR signalling pathways in breast cancer cell. Binding of oestrogen to ER stimulates activation of signalling in cytoplams, dimerisation of ER and downstream nuclear signalling. Oestrogen/ER-induced activation of SphK1 results in reduction of sphingosine cell content and production of S1P. S1P activates further downstream signalling targets including cdc42, extracellular transport systems of S1P, phosphorylation of S1P receptors, transactivation of EGFR and its recycling. Cav-1, caveolin-1; ER, oestrogen receptor; $E R E$, oestrogen response element; $E G F$, epidermal growth factor; EGFR, EGF receptor; HB-EGF, heparin-bound EGF; $G \alpha, \beta, \gamma$, G-protein subunits; GPR30, G-protein-coupled receptor 30; MMPs, matrix metalloproteases; cdc42, cell division control protein 42; Src, non-receptor tyrosine kinase; SphK1, human sphingosine kinase 1; S1P, sphingosine-1-phosphate. http://joe.endocrinology-journals.org DOI: 10.1530/JOE-13-0388 (c) 2014 The authors Printed in Great Britain
Published by Bioscientifica Ltd 
Elevated S1P levels generated by the ectopic expression of SPHK1 not only enhanced the mitogenic effects of oestrogen (Sukocheva et al. 2003) but also blocked apoptosis induced by anti-cancer drugs, sphingosine and tumour necrosis factor $\alpha$ (Nava et al. 2002). The ER antagonist ICI 182780 prevented the oestrogeninduced SphK1 activation, suggesting that ER $\alpha$ is the most likely candidate required for SphK1 activation (Sukocheva et al. 2006). Oestrogen did not stimulate SphK1 activation in ER $\alpha$-negative cells and also in cells with downregulated ER $\alpha$ (Sukocheva et al. 2006), supporting ER $\alpha$-dependent link to SphK1 signalling.

Cytoplasmic signalling cascades activated by oestrogen are tissue specific and depend on expression of several forms of membrane-associated ERs including G-proteincoupled receptor 30 (GPR30; Driggers \& Segars 2002, Filardo \& Thomas 2012). The role of GPR30 in the oestrogen-induced activation of SphK1 has been detected. Downregulation of GPR30 expression by its antisense oligonucleotides significantly inhibited $\beta$-oestradiol $\left(\mathrm{E}_{2}\right)$ induced SphK1 activity in MCF-7 human BCC (Sukocheva et al. 2006). Interestingly, in these cells a phytoestrogen genistein, which can also activate signalling through GPR30 (Thomas \& Dong 2006), has been shown to regulate sphingolipid metabolism by a different mechanism. Genistein stimulated transcription of acid ceramidase (ASAH1) in MCF-7 cells (Lucki \& Sewer 2011). Acid ceramidase degrades ceramide and, thus, provides a supply of sphingosine which, in turn, can be phosphorylated by SphK1 and transformed into S1P (Fig. 1), maintaining growth and survival signals. The mechanism of this phytoestrogen-induced activation of ASAH1 appears complex. Genistein induces $A S A H 1$ transcription through a GPR30-dependent, pertussis toxin-sensitive pathway that requires the activation of c-Src and ERK1/2. Activation of this pathway promotes histone acetylation and recruitment of phospho-ER $\alpha$ and specificity protein-1 to the ASAH1 promoter, ultimately culminating in increased ceramidase activity (Lucki \& Sewer 2011). The mechanism of prolonged activation of SphK1 by $\mathrm{E}_{2}$ is less clear. Hypothetically, it might work within a similar scheme shown for phytoestrogen signalling in MCF-7 cells. Supporting this both, GPR30 and ER $\alpha$ were involved in oestrogen-dependent activation of SphK1 (Sukocheva et al. 2003, 2006, Doll et al. 2007). The exact mechanisms underlying rapid (15-30 min) SphK1 activation by $\mathrm{E}_{2}$ also remain elusive, leaving the possibility of direct or adaptormediated interactions between ER $\alpha$, GPR30 and SphK1 still unexplored.
Interestingly, although both oestrogen and EGF were able to activate SphK1 and increase intracellular levels of S1P, only oestrogen can stimulate rapid release of S1P and dihydro-S1P from BCCs (Takabe et al. 2010). Oestrogeninduced S1P export required the presence of functional $E R \alpha$, but not GPR30, and was suppressed either by pharmacological inhibitors or gene silencing of multidrug resistant protein 1 (ABCC1) or breast cancer resistance protein (ABCG2). Thus, activation of ABCC1 and/or ABCG2 might participate in oestrogen-dependent activation of S1P receptors and contribute to oestrogen signalling (Takabe et al. 2010), which is important for breast cancer pathophysiology. However, the role of other potential S1P transmembrane transporting mechanisms should be further explored in ER-positive cancer cells. For instance, in the vasculature S1P signalling activity was modulated by several different transporters including cystic fibrosis transmembrane regulator, cAMP-responsive chloride channel (Meissner et al. 2012), and by S1P transporter spinster homolog 2 (Spns2) protein (Fukuhara et al. 2012).

It has been demonstrated that the oestrogen signalling pathway overwhelms the growth factor network in BCCs, thereby facilitating cancer cell proliferation and survival. For instance, IGF receptor type 1 (IGFR1) and EGF receptors (EGFR) are transactivated by oestrogens in various cancer cells (Driggers \& Segars 2002). S1P stimulates BCC growth through activation of the serum response element and indirectly by enhancing IGF2 synthesis and function (Goetzl et al. 1999a,b). Neutralising antibodies against IGFR1 strongly suppressed cell proliferation induced by S1P (Goetzl et al. 1999a,b). It was also demonstrated in human embryonic kidney 293 cells that IGF2 binding to the IGF2/mannose-6-phosphate (M6P) receptor activates the ERK1/2 cascade by triggering SphK1dependent transactivation of G-protein-coupled S1P receptors (El-Shewy et al. 2006). Activation of both phospholipase $C$ and protein kinase $C$ isoform $\beta 2$ by the IGF2/M6P receptor was required for the activation of SphK1 during this process (El-Shewy et al. 2011). By contrast, Nava and colleagues did not find any significant impact of IGFR1 on SphK1 signalling in BCCs (Nava et al. 2002).

Another growth factor, EGF, increases the expression of SphK1 in MCF-7 BCC (Doll et al. 2005). Notably, SphK1 is required for EGF-induced BCC migration, proliferation and cell survival (Sarkar et al. 2005, Sukocheva et al. 2006). We have found that the oestrogen-induced transactivation of EGFR is mediated through the SphK1/S1P pathway. Both ER $\alpha$ and GPR30 were important for initiation of this

Published by Bioscientifica Ltd

Downloaded from Bioscientifica.com at $04 / 26 / 2023$ 11:22:11AM via free access 
signaling. S1P, generated by the oestrogen-induced SphK1, acts through the $\mathrm{S}_{1} \mathrm{P}_{3}$ receptor to activate the EGFR via a pathway mediated by Src and matrix metalloproteases (Sukocheva et al. 2006; Fig. 2). Thus, SphK1 served as a key factor in coupling the signals between three membrane spanning events induced by oestrogen, S1P and EGF resulting in mitogenic stimulation of BCCs.

Significant differences have been recently demonstrated between the signalling mechanisms of liganddependent and ligand-independent activation of EGFR (Sukocheva et al. 2013). $\mathrm{E}_{2}$ and S1P stimulation induces elevated EGFR in MCF-7 endosomes, although the plasma membrane-associated, transactivated EGFRs are quickly internalised. Both $\mathrm{E}_{2}$ and S1P induce prolonged activation of cell division cycle protein 42 , a member of the Rho family of small GTPases involved in the regulation of protein turnover, thereby inhibiting EGFR degradation and maintaining elevated levels of EGFR (Sukocheva et al. 2013; Fig. 2), which may account, at least partially, for the enhanced mitogenic signalling in BCCs. SphK/S1P signalling system is often upregulated in many types of cancer including breast cancer (Watson et al. 2010). Therefore, we reasoned that S1P receptor-mediated regulation of EGFR internalisation and activation was probably hijacked and adapted by cancer cells to secure survival and neoplastic growth (Sukocheva et al. 2013).

Overexpression of EGF receptor 2 (HER2) stimulates expression of SphK1 in ER $\alpha$-positive BCCs. SphK1, in turn, limits HER2 expression in a negative-feedback manner (Long et al. 2010). The mechanism associated with this mutual interaction between the sphingolipid pathway and growth factor receptor-initiated cascades was termed 'oncogene tolerance' (Long et al. 2010). These findings correlated with improved prognosis in patients who have a low HER1-3/SPHK1 expression ratio in their ER $\alpha$-positive breast cancer tumours (Long et al. 2010). The therapeutic importance of targeting the SphK pathway was further supported by microarray analysis of 750 patients with ER $\alpha$ positive breast tumours. Poor disease outcome correlated with high SPHK1 expression, while $75.8+1.9 \%$ of the patients with tumours low in SphK1 were free of metastasis at 5 years (Ruckhäberle et al. 2008).

\section{Contribution of sphingolipid signalling in development of drug resistance}

Acquired chemoresistance is an unfortunate impediment accounting for major failure of cancer therapy. In the search for novel cancer treatment targets, several recent studies have addressed the involvement of sphingolipid signalling in the development of cancer drug resistance (Sukocheva et al. 2009, Antoon et al. 2010, 2012, Watson et al. 2010).

A correlation between tamoxifen responsiveness, the levels of SPHK1 expression and its activity has been detected in MCF-7 BCC (Sukocheva et al. 2009). Overexpression of SPHK1 markedly reduced tamoxifen-induced cell growth arrest and apoptosis in the anti-oestrogen-sensitive MCF-7 BCC. Accordingly, tamoxifen-resistant cells selected by prolonged exposure to tamoxifen exhibited elevated SPHK1 expression and activity (Sukocheva et al. 2009). Furthermore, inhibiting SphK1 activity by either chemical inhibitors or the dominant-negative mutant $\mathrm{SphK} 1^{\mathrm{G} 82 \mathrm{D}}$ significantly enhanced the anti-proliferative and proapoptotic effects of tamoxifen (Sukocheva et al. 2009). And finally, downregulation of SPHK1 expression restored tamoxifen sensitivity (Sukocheva et al. 2009). These findings revealed a pivotal role of SphK1 in the regulation of cell sensitivity to the widely used breast cancer chemotherapy agent tamoxifen, suggesting that the anti-oestrogen responses can be reprogrammed by manipulating the SphK1 pathway (Sukocheva et al. 2009, Watson et al. 2010).

Notably, inhibition of either the ${\mathrm{S} 1 \mathrm{P}_{3}}_{3}$ receptor or EGFR restored tamoxifen responsiveness to the same extent seen in tamoxifen-resistant MCF-7 BCC treated with the SphK inhibitors (Sukocheva et al. 2009), substantiating a critical role for $\mathrm{S}_{1} \mathrm{P}_{3} / \mathrm{EGFR}$ transactivation in tamoxifen resistance. An enhanced $\mathrm{S}_{1} \mathrm{P}_{3} / \mathrm{EGFR}$ signalling axis may also contribute to the tumourigenesis in different tissues, where oncogenic role of growth factor signalling has been confirmed (Duffy 2013). For instance, $\mathrm{S}_{1} \mathrm{P}_{3}$ signalling increases EGFR expression via the Rho kinase pathway in lung adenocarcinoma cells (Hsu et al. 2012). The role of other S1P receptors should also be addressed considering the recent evidence that $\mathrm{S}_{1} \mathrm{P}_{1}$ receptor signalling plays a significant role in, for instance, progression of hepatocellular carcinoma (Bao et al. 2012).

As a single cancer cell can express several types of S1P receptor, it is unclear whether the ratio of various S1P receptors serves as a regulator of growth signals within one particular cell and in cell-to-cell communication. S1P receptors stimulate diverse signalling pathways that might be mutually exclusive in the regulation of cell proliferation and migration signals. A complex type of interplay among S1P receptors was demonstrated in malignant cells (Young \& Van Brocklyn 2007). However, there has been specific interest in $\mathrm{S}_{1} \mathrm{P}_{2}$ signalling (Takuwa et al. 2011). In sharp contrast to the growth and migration-promoting characteristics of $\mathrm{S}_{1} \mathrm{P}_{3}, \mathrm{~S}_{1} \mathrm{P}_{2}$ mediates Rac inhibition

Published by Bioscientifica Ltd 
downstream of G(12/13)-mediated Rho activation, thus identifying it as the first GPR negatively regulating Rac and cell migration. ${\mathrm{S} 1 \mathrm{P}_{2}}_{2}$ may also inhibit Akt and cell proliferation/survival signalling via the Rho/ROCK/PTEN pathway (Sanchez et al. 2005, Takuwa et al. 2011). Moreover, $\mathrm{S}_{1} \mathrm{P}_{2}$ expressed in host endothelial cells and tumour-infiltrating myeloid cells mediates potent inhibition of tumour angiogenesis and tumour growth in vivo by inhibiting VEGF expression and MMP9 activity (Du et al. 2010, Takuwa et al. 2012). However, the role of $\mathrm{S}_{2} \mathrm{P}_{2}$ has never been addressed as a potential target in drug resistant BCCs.

Associations between SphK/S1P receptor expression and clinical outcomes were further explored in a few recent clinical studies. In a cohort of 304 breast cancer patients, the higher expression levels of $\mathrm{S}_{1} \mathrm{P}_{1}, \mathrm{~S}_{1} \mathrm{P}_{3}$ and ERK1/2 were associated with the shorter recurrence times in ER-positive breast cancer patients (Watson et al. 2010). High cytoplasmic $\mathrm{S}_{1} \mathrm{P}_{1}$ and $\mathrm{S}_{1} \mathrm{P}_{3}$ expression levels were also associated with shorter disease-specific survival times. Those patients with tumours expressing high levels of both cytoplasmic SphK1 and ERK1/2 had significantly shorter recurrence times than those expressing low levels of cytoplasmic SphK1 and ERK1/2, with a difference in recurrence time of 10.5 years. Similarly, high cytoplasmic $\mathrm{S}_{1} \mathrm{P}_{1}$ and ERK1/2 expression levels and high cytoplasmic ${\mathrm{S} 1 \mathrm{P}_{3}}_{3}$ and ERK1/2 expression levels were associated with shorter recurrence times. These results support a model in which the interaction between $\mathrm{SphK} 1, \mathrm{~S}_{1} \mathrm{P}_{1}$, and/or $\mathrm{S}_{1} \mathrm{P}_{3}$ and ERK1/2 might drive breast cancer progression (Watson et al. 2010). Moreover, the higher level of $\mathrm{S} \mathrm{P}_{3}$ may potentially be associated with metastatic progression. ${\mathrm{S} 1 \mathrm{P}_{3}}_{3}$ induces a migratory phenotype via a SphK1dependent mechanism in ER-positive BCCs (Long et al. 2010), transmits stimulatory signals for breast cell proliferation (Sukocheva et al. 2006, Martin et al. 2009) and activates anti-apoptotic mechanisms (Nava et al. 2002, Doll et al. 2005).

The role of the $\mathrm{S} \mathrm{P}_{4}$ receptor was highlighted in ER-negative breast cancer patients (Ohotski et al. 2012). High $\mathrm{S}_{1} \mathrm{P}_{4}$ expression was associated with shorter diseasefree and disease-specific survival in a cohort of 140 patients with ER-negative BCCs. In addition, patients with tumours containing high SphK1 and low $\mathrm{S}_{1} \mathrm{P}_{4}$ had a significantly shorter disease-free survival and diseasespecific survival compared with patients whose tumours contain low levels of both $\mathrm{S}_{1} \mathrm{P}_{4}$ and SphK1. High tumour expression of SphK1 was also significantly associated with HER2-positivity (Ohotski et al. 2012), indicating on the possible intrinsic link between systems of growth factor signalling and sphingolipid metabolism that has to be further explored.

\section{Studies with SphK inhibitors and S1P receptor agonists}

SphK1's regulation of BCCs tamoxifen sensitivity is also associated with the potent anti-apoptotic properties of S1P signalling (Hait et al. 2006). Although the precise mechanisms remain to be identified, S1P's anti-apoptotic effects have been connected to impaired activation of protein kinase JNK (Edsall et al. 2001), caspases (Cuvillier et al. 1998, Xia et al. 1999, Nava et al. 2002), alterations in the ratio between pro- and anti-apoptotic members of the Bcl2 family (Goetzl et al. 1999a,b, Limaye et al. 2005) and reduced cytochrome $c$ and Smac/DIABLO release from mitochondria (Cuvillier et al. 2001). The house-keeping removal of sphingosine by SphK1 could be also responsible, at least in part, for the observed anti-apoptotic effect (Cuvillier et al. 2001).

SphK inhibition by ABC294640 (3-(4-chlorophenyl)adamantane-1-carboxylic acid (pyridin-4-ylmethyl) amide) has recently been shown to activate several targets associated with the induction of cell death in BCCs. These include inhibition of the NF- $\mathrm{BB}$ pathway, blockade of ER signalling and activation of autophagy.

NF- $\kappa \mathrm{B}$ is a pivotal molecule intersecting various signalling pathways that translates a wide range of cytoplasmic signals into specific gene activation (Hayden $\&$ Ghosh 2012). According to Montagut et al. (2006), chemoresistance correlated well with NF- $\kappa \mathrm{B}$ activation in tumour specimens from breast cancer patients. Interestingly, pharmacological inhibition of SphK blocks NF-кB transcriptional activation and induces the intrinsic apoptosis pathway in multi-drug-resistant BCCs (Antoon et al. 2012). The SphK inhibitor ABC294640 diminished NF- $\mathrm{BB}$ survival signalling, through decreased phosphorylation of Ser536 on the p65 subunit. This inhibitor also completely blocks tumour volume in xenograft models of chemoresistant BCCs growing in immuno-compromised mice in vivo, indicating therapeutic efficacy of this inhibitor (Antoon et al. 2011b).

The details of another inhibitory mechanism activated by the SphK inhibitor ABC294640 have been demonstrated by Beljanski et al. (2010). ABC294640induced non-apoptotic cell death preceded by cleavage of the microtubule-associated protein light chain 3 , morphological changes in lysosomes, formation of autophagosomes, and increases in the number of acidic vesicles. These ABC294640-induced autophagic responses

Published by Bioscientifica Ltd 
in A-498 kidney, PC-3 prostate and MDA-MB-231 (ER-negative) breast adenocarcinoma cells suggest that there is a universal signalling mechanism for this compound within transformed cells. Simultaneous exposure of tumour cells to ABC294640 and 3-methyladenine, an inhibitor of autophagy, switched the toxic mechanism to apoptosis, but decreased the potency of the SphK inhibitor, suggesting that autophagy might be one of the mechanisms used for killing tumour cell by this compound (Beljanski et al. 2010).

Notably, it appears that SphK inhibitors have the ability to influence multiple targets. ABC294640 has been also shown to bind to the ligand-binding domain of $\mathrm{ER} \alpha$, acting as a partial antagonist, similar to tamoxifen (Antoon et al. 2010). Thus, it is possible that SphK inhibitors have the capacity to act as novel anti-oestrogens in breast carcinomas (Antoon et al. 2010, 2011a). Supporting this, similar intervention in the ER-signalling pathway has been noted for different SphK inhibitors. The SphK1/2-selective inhibitor (SKI-II) dose-dependently decreased oestrogenstimulated oestrogen-responsive element transcriptional activity and diminished mRNA levels of the ER-regulated genes, such as the progesterone receptor and steroidderived factor-1 (Antoon et al. 2010). Considering that ER antagonists had been successfully used for the treatment of ER-positive breast cancer patients (about 70\% of all breast cancer patients) for several decades and that BCCs from these patients rely mainly on ER proliferative signals, the effects of these SphK inhibitors appear promising.

The SphK inhibitors described above are not the only group of pharmacological substances that can modulate sphingolipid signalling and activate autophagy. A sphingosine analogue and specific S1P receptor ligand, FTY720, demonstrated anti-cancer potential inducing cellular swelling, cytoplasmic vacuolisation with evident features of necrotic cell death (Zhang et al. 2010). Phosphorylated by SphK, FTY720 acts on the S1P receptor inducing the S1P receptor internalisation in lymphocytes, silencing S1P signalling and sequestering receptors in the lymph nodes, while decreasing circulating $\mathrm{T}$ cells (Brinkmann \& Lynch 2002). In clinical trials so far, FTY720 has proved somewhat disappointing due to serious adverse effects such as cardiac arrest emphasising, however, the prominent role of sphingolipids in the vasculature (Cyster \& Schwab 2012). Considering the systemic effects of FTY720, further studies are needed to improve delivery and specificity of pharmacological agonists/antagonists of sphingolipid signalling.

The need to explore S1P receptor agonists in clinical settings has been supported by data from in vivo murine breast cancer metastasis model. Pharmacological inhibition of SphK1 and suppressed S1P levels thereby reduced metastases to lymph nodes and lungs, and decreased overall tumour burden. Notably, SK1-I decreased both processes not only in the primary tumour but also in lymph nodes, with peritumoural lymphatic vessel density reduced in SK1-I-treated animals (Nagahashi et al. 2012). A clinical research study conducted last year showed that serum S1P levels are significantly elevated in stage IIIA human breast cancer patients compared with age/ ethnicity-matched healthy volunteers (Nagahashi et al. 2012), emphasising the need to further explore the anticancer role of various S1P receptor inhibitors.

\section{Conclusions}

Recent advances in the field of sphingolipid signalling in breast cancers clearly indicate that sphingolipids play critical, yet incompletely understood, roles in the regulation of tumour growth and spread. There are still significant gaps in our understanding of how oestrogen and sphingolipid signalling networks interact. However, there are multiple indications that sphingolipid-signalling modulating agents have potent therapeutic efficacy against cancer. For instance, tamoxifen sensitivity is restored by inhibiting SphK1 signalling (Sukocheva et al. 2009), which has also been shown for other chemotherapeutic drugs including doxorubicin (Antoon et al. 2012). We are now only starting to understand how sphingolipids coordinate the multiple mitogenic signals leading to neoplastic cell growth and cancer development. Further design and exploration of SphK and S1P receptor agonists and antagonists are required to improve endocrine therapeutic response and management of breast cancers.

\begin{abstract}
Declaration of interest
The authors declare that there is no conflict of interest that could be perceived as prejudicing the impartiality of the research reported.
\end{abstract}

\section{Funding}

This work was supported by grants from C.M.E. Kelly Cancer Research Foundation and Lyn Wrigley Breast Cancer Research and Development Fund (Flinders Medical Centre, Australia; to O S).

\section{Author contribution statement}

O S conceived and designed the studies. OS and CW contributed equally to the paper writing.

Published by Bioscientifica Ltd 


\section{Acknowledgements}

The authors thank Dr P Xia for critical reading of the manuscript.

\section{References}

Alvarez SE, Milstien S \& Spiegel S 2007 Autocrine and paracrine roles of sphingosine-1-phosphate. Trends in Endocrinology and Metabolism 18 300-307. (doi:10.1016/j.tem.2007.07.005)

Antoon JW, White MD, Meacham WD, Slaughter EM, Muir SE, Elliott S, Rhodes LV, Ashe HB, Wiese TE, Smith CD et al. 2010 Antiestrogenic effects of the novel sphingosine kinase-2 inhibitor ABC294640. Endocrinology 151 5124-5135. (doi:10.1210/en.2010-0420)

Antoon JW, Meacham WD, Bratton MR, Slaughter EM, Rhodes LV, Ashe HB, Wiese TE, Burow ME \& Beckman BS 2011a Pharmacological inhibition of sphingosine kinase isoforms alters estrogen receptor signaling in human breast cancer. Journal of Molecular Endocrinology 46 205-216. (doi:10.1530/JME-10-0116)

Antoon JW, White MD, Slaughter EM, Driver JL, Khalili HS, Elliott S, Smith CD, Burow ME \& Beckman BS 2011b Targeting NFkB mediated breast cancer chemoresistance through selective inhibition of sphingosine kinase-2. Cancer Biology \& Therapy 11 678-689. (doi:10.4161/cbt.11.7.14903)

Antoon JW, White MD, Burow ME \& Beckman BS 2012 Dual inhibition of sphingosine kinase isoforms ablates TNF-induced drug resistance. Oncology Reports 27 1779-1786. (doi:10.3892/or.2012.1743)

Aoyagi T, Nagahashi M, Yamada A \& Takabe K 2012 The role of sphingosine-1-phosphate in breast cancer tumor-induced lymphangiogenesis. Lymphatic Research and Biology 10 97-106. (doi:10.1089/ lrb.2012.0010)

Auge N, Garcia V, Maupas-Schwalm F, Levade T, Salvayre R \& Negre-Salvayre A 2002 Oxidized LDL-induced smooth muscle cell proliferation involves the EGF receptor/PI-3 kinase/Akt and the sphingolipid signaling pathways. Arteriosclerosis, Thrombosis, and Vascular Biology 22 1990-1995. (doi:10.1161/01.ATV.0000043453. 21629.3B)

Bao M, Chen Z, Xu Y, Zhao Y, Zha R, Huang S, Liu L, Chen T, Li J, Tu H et al. 2012 Sphingosine kinase 1 promotes tumour cell migration and invasion via the S1P/EDG1 axis in hepatocellular carcinoma. Liver International 32 331-338. (doi:10.1111/j.1478-3231.2011.02666.x)

Beljanski V, Knaak C \& Smith CD 2010 A novel sphingosine kinase inhibitor induces autophagy in tumor cells. Journal of Pharmacology and Experimental Therapeutics 333 454-464. (doi:10.1124/jpet.109.163337)

Brinkmann V \& Lynch KR 2002 FTY720: targeting G-protein-coupled receptors for sphingosine 1-phosphate in transplantation and autoimmunity. Current Opinion in Immunology 14 569-575. (doi:10.1016/ S0952-7915(02)00374-6)

Chipuk JE, McStay GP, Bharti A, Kuwana T, Clarke CJ, Siskind LJ, Obeid LM \& Green DR 2012 Sphingolipid metabolism cooperates with BAK and BAX to promote the mitochondrial pathway of apoptosis. Cell $\mathbf{1 4 8}$ 988-1000. (doi:10.1016/j.cell.2012.01.038)

Contreras FX, Ernst AM, Haberkant P, Björkholm P, Lindahl E, Gönen B, Tischer C, Elofsson A, von Heijne G, Thiele C et al. 2012 Molecular recognition of a single sphingolipid species by a protein's transmembrane domain. Nature $\mathbf{4 8 1} 525-529$. (doi:10.1038/nature10742)

Cuvillier O, Pirianov G, Kleuser B, Vanek PG, Coso OA, Gutkind S \& Spiegel S 1996 Suppression of ceramide-mediated programmed cell death by sphingosine-1-phosphate. Nature 381 800-803. (doi:10.1038/ 381800a0)

Cuvillier O, Rosenthal DS, Smulson ME \& Spiegel S 1998 Sphingosine 1-phosphate inhibits activation of caspases that cleave poly (ADP-ribose) polymerase and lamins during Fas- and ceramidemediated apoptosis in Jurkat T lymphocytes. Journal of Biological Chemistry 273 2910-2916. (doi:10.1074/jbc.273.5.2910)
Cuvillier O, Nava VE, Murthy SK, Edsall LC, Levade T, Milstien S \& Spiegel S 2001 Sphingosine generation, cytochrome $c$ release, and activation of caspase-7 in doxorubicin-induced apoptosis of MCF7 breast adenocarcinoma cells. Cell Death and Differentiation 8 162-171. (doi:10.1038/sj.cdd.4400793)

Cyster JG \& Schwab SR 2012 Sphingosine-1-phosphate and lymphocyte egress from lymphoid organs. Annual Review of Immunology 30 69-94. (doi:10.1146/annurev-immunol-020711-075011)

Döll F, Pfeilschifter J \& Huwiler A 2005 The epidermal growth factor stimulates sphingosine kinase-1 expression and activity in the human mammary carcinoma cell line MCF7. Biochimica et Biophysica Acta 1738 $72-81$.

Doll F, Pfeilschifter J \& Huwiler A 2007 Prolactin upregulates sphingosine kinase-1 expression and activity in the human breast cancer cell line MCF7 and triggers enhanced proliferation and migration. Endocrine-Related Cancer 14 325-335. (doi:10.1677/ERC-06-0050)

Driggers PH \& Segars JH 2002 Estrogen action and cytoplasmic signaling pathways. Part II: the role of growth factors and phosphorylation in estrogen signaling. Trends in Endocrinology and Metabolism 13 422-427. (doi:10.1016/S1043-2760(02)00634-3)

Du W, Takuwa N, Yoshioka K, Okamoto Y, Gonda K, Sugihara K, Fukamizu A, Asano M \& Takuwa Y 2010 S1P(2), the G protein-coupled receptor for sphingosine-1-phosphate, negatively regulates tumor angiogenesis and tumor growth in vivo in mice. Cancer Research 70 772-781. (doi:10.1158/0008-5472.CAN-09-2722)

Duffy MJ 2013 The war on cancer: are we winning? Tumour Biology 34 1275-1284. (doi:10.1007/s13277-013-0759-2)

Edsall LC, Cuvillier O, Twitty S, Spiegel S \& Milstien S 2001 Sphingosine kinase expression regulates apoptosis and caspase activation in PC12 cells. Journal of Neurochemistry 76 1573-1584. (doi:10.1046/j.14714159.2001.00164.x)

El-Shewy HM, Johnson KR, Lee MH, Jaffa AA, Obeid LM \& Luttrell LM 2006 Insulin-like growth factors mediate heterotrimeric $\mathrm{G}$ proteindependent ERK1/2 activation by transactivating sphingosine-1phosphate receptors. Journal of Biological Chemistry 281 31399-31407. (doi:10.1074/jbc.M605339200)

El-Shewy HM, Abdel-Samie SA, Al Qalam AM, Lee MH, Kitatani K, Anelli V, Jaffa AA, Obeid LM \& Luttrell LM 2011 Phospholipase C and protein kinase C- $\beta 2$ mediate insulin-like growth factor II-dependent sphingosine kinase 1 activation. Molecular Endocrinology 25 2144-2156. (doi:10.1210/me.2011-0101)

English D, Kovala AT \& Welch Z 1999 Induction of endothelial cell chemotaxis by sphingosine 1-phosphate and stabilization of endothelial monolayer barrier function by lysophosphatidic acid, potential mediators of hematopoietic angiogenesis. Journal of Hematotherapy \& Stem Cell Research 8 627-634. (doi:10.1089/152581699319795)

Filardo EJ \& Thomas P 2012 Minireview: G protein-coupled estrogen receptor-1, GPER-1: its mechanism of action and role in female reproductive cancer, renal and vascular physiology. Endocrinology 153 2953-2962. (doi:10.1210/en.2012-1061)

French KJ, Schrecengost RS, Lee BD, Zhuang Y, Smith SN, Eberly JL, Yun JK \& Smith CD 2003 Discovery and evaluation of inhibitors of human sphingosine kinase. Cancer Research 63 5962-5969.

Fukuhara S, Simmons S, Kawamura S, Inoue A, Orba Y, Tokudome T, Sunden Y, Arai Y, Moriwaki K, Ishida J et al. 2012 The sphingosine1-phosphate transporter Spns2 expressed on endothelial cells regulates lymphocyte trafficking in mice. Journal of Clinical Investigation 122 1416-1426. (doi:10.1172/JCI60746)

Furuya H, Shimizu Y \& Kawamori T 2011 Sphingolipids in cancer. Cancer Metastasis Reviews 30 567-576. (doi:10.1007/s10555-011-9304-1)

Gao P, Peterson YK, Smith RA \& Smith CD 2012 Characterization of isoenzyme-selective inhibitors of human sphingosine kinase. PLOS ONE 7 e44543. (doi:10.1371/journal.pone.0044543)

Goetzl EJ, Dolezalova H, Kong Y \& Zeng L 1999a Dual mechanisms for lysophospholipid induction of proliferation of human breast carcinoma cells. Cancer Research 59 4732-4737. 
Goetzl EJ, Kong Y \& Mei B 1999b Lysophosphatidic acid and sphingosine 1-phosphate protection of $\mathrm{T}$ cells from apoptosis in association with suppression of Bax. Journal of Immunology 162 2049-2056.

Hait NC, Oskeritzian CA, Paugh SW, Milstien S \& Spiegel S 2006 Sphingosine kinases, sphingosine 1-phosphate, apoptosis and diseases. Biochimica et Biophysica Acta 1758 2016-2026. (doi:10.1016/j.bbamem. 2006.08.007)

Hait NC, Allegood J, Maceyka M, Strub GM, Harikumar KB, Singh SK, Luo C, Marmorstein R, Kordula T, Milstien S et al. 2009 Regulation of histone acetylation in the nucleus by sphingosine-1-phosphate. Science $\mathbf{3 2 5}$ 1254-1257. (doi:10.1126/science.1176709)

Hänel P, Andréani P \& Gräler MH 2007 Erythrocytes store and release sphingosine 1-phosphate in blood. FASEB Journal 21 1202-1209. (doi:10.1096/fj.06-7433com)

Hannun YA \& Obeid LM 2008 Principles of bioactive lipid signalling: lessons from sphingolipids. Nature Reviews. Molecular Cell Biology 9 139-150. (doi:10.1038/nrm2329)

Hayden MS \& Ghosh S 2012 NF- $\kappa$ B, the first quarter-century: remarkable progress and outstanding questions. Genes and Development 26 203-234. (doi:10.1101/gad.183434.111)

Hobson JP, Rosenfeldt HM, Barak LS, Olivera A, Poulton S, Caron MG, Milstien S \& Spiegel S 2001 Role of the sphingosine-1-phosphate receptor EDG-1 in PDGF-induced cell motility. Science 291 1800-1803. (doi:10.1126/science.1057559)

Holthuis JC, Pomorski T, Raggers RJ, Sprong H \& Van Meer G 2001 The organizing potential of sphingolipids in intracellular membrane transport. Physiological Reviews 81 1689-1723.

Hsu A, Zhang W, Lee JF, An J, Ekambaram P, Liu J, Honn KV, Klinge CM \& Lee MJ 2012 Sphingosine-1-phosphate receptor-3 signaling upregulates epidermal growth factor receptor and enhances epidermal growth factor receptor-mediated carcinogenic activities in cultured lung adenocarcinoma cells. International Journal of Oncology $\mathbf{4 0}$ 1619-1626. (doi:10.3892/ijo.2012.1379)

Kveberg L, Bryceson Y, Inngjerdingen M, Rolstad B \& Maghazachi AA 2003 Sphingosine 1 phosphate induces the chemotaxis of human natural killer cells. Role for heterotrimeric $\mathrm{G}$ proteins and phosphoinositide 3 kinases. European Journal of Immunology 32 1856-1864. (doi:10.1002/ 1521-4141(200207)32:7\%3C;1856::AID-IMMU1856\%3E;3.0.CO;2-B)

Lebman DA \& Spiegel S 2008 Cross-talk at the crossroads of sphingosine1-phosphate, growth factors, and cytokine signaling. Journal of Lipid Research 49 1388-1394. (doi:10.1194/jlr.R800008-JLR200)

Leclercq TM, Moretti PAB, Vadas MA \& Pitson SM 2008 Eukaryotic elongation factor $1 \mathrm{~A}$ interacts with sphingosine kinase and directly enhances its catalytic activity. Journal of Biological Chemistry 283 9606-9614. (doi:10.1074/jbc.M708782200)

Lee OH, Kim YM \& Lee YM 1999 Sphingosine-1-phosphate induces angiogenesis: its angiogenic action and signaling mechanism in human umbilical vein endothelial cells. Biochemical and Biophysical Research Communications 264 743-750. (doi:10.1006/bbrc.1999.1586)

Limaye V, Li X, Hahn C, Xia P, Berndt MC, Vadas MA \& Gamble JR 2005 Sphingosine kinase-1 enhances endothelial cell survival through a PECAM-1-dependent activation of PI-3K/Akt and regulation of Bcl-2 family members. Blood 105 3169-3177. (doi:10.1182/blood-200402-0452)

Liu H, Toman RE, Goparaju SK, Maceyka M, Nava VE, Sankala H, Payne SG, Bektas M, Ishii I, Chun J et al. 2003 Sphingosine kinase type 2 is a putative BH3-only protein that induces apoptosis. Journal of Biological Chemistry 278 40330-40336. (doi:10.1074/jbc.M304455200)

Long JS, Edwards J, Watson C, Tovey S, Mair KM, Schiff R, Natarajan V, Pyne NJ \& Pyne S 2010 Sphingosine kinase 1 induces tolerance to human epidermal growth factor receptor 2 and prevents formation of a migratory phenotype in response to sphingosine 1-phosphate in estrogen receptor-positive breast cancer cells. Molecular and Cellular Biology 30 3827-3841. (doi:10.1128/MCB.01133-09)

Lucki NC \& Sewer MB 2011 Genistein stimulates MCF-7 breast cancer cell growth by inducing acid ceramidase (ASAH1) gene expression.
Journal of Biological Chemistry 286 19399-19409. (doi:10.1074/jbc. M110.195826)

Martin JL, Lin MZ, McGowan EM \& Baxter RC 2009 Potentiation of growth factor signaling by insulin-like growth factor-binding protein-3 in breast epithelial cells requires sphingosine kinase activity. Journal of Biological Chemistry 284 25542-25552. (doi:10.1074/jbc.M109.007120)

Matloubian M, Lo CG \& Cinamon G 2004 Lymphocyte egress from thymus and peripheral lymphoid organs is dependent on S1P receptor 1. Nature 427 355-360. (doi:10.1038/nature02284)

Meacham WD, Antoon JW, Burow ME, Struckhoff AP \& Beckman B 2009 Sphingolipids as determinants of apoptosis and chemoresistance in the MCF-7 cell model system. Experimental Biology and Medicine 234 1253-1263. (doi:10.3181/0902-MR-77)

Meissner A, Yang J, Kroetsch JT, Sauvé M, Dax H, Momen A, Noyan-Ashraf MH, Heximer S, Husain M, Lidington D et al. 2012 TNF $\alpha$-mediated down-regulation of CFTR drives pathological S1P signaling in a mouse model of heart failure. Circulation 125 2739-2750. (doi:10.1161/CIRCULATIONAHA.111.047316)

Montagut C, Tusquets I, Ferrer B, Corominas JM, Bellosillo B, Campas C, Suarez M, Fabregat X, Campo E, Gascon P et al. 2006 Activation of $\mathrm{NF}-\kappa \mathrm{B}$ is linked to resistance to neoadjuvant chemotherapy in breast cancer patients. Endocrine-Related Cancer 13 607-616. (doi:10.1677/ erc.1.01171)

Nagahashi M, Ramachandran S, Kim EY, Allegood JC, Rashid OM, Yamada A, Zhao R, Milstien S, Zhou H, Spiegel S et al. 2012 Sphingosine1-phosphate produced by sphingosine kinase 1 promotes breast cancer progression by stimulating angiogenesis and lymphangiogenesis. Cancer Research 72 726-735. (doi:10.1158/0008-5472.CAN-11-2167)

Nakade Y, Bano Y, Koizume KT, Hagiwara K, Sobue S, Koda M, Suzuki M, Kojima T, Takagi A, Asano H et al. 2003 Regulation of sphingosine kinase 1 gene expression by protein kinase $\mathrm{C}$ in human leukaemia cell line MEG-O1. Biochimica et Biophysica Acta 1635 104-116. (doi:10.1016/j.bbalip.2003.11.001)

Nava VE, Hobson JP, Murthy S, Milstien S \& Spiegel S 2002 Sphingosine kinase type 1 promotes estrogen-dependent tumorigenesis of breast cancer MCF-7 cells. Experimental Cell Research 281 115-127. (doi:10.1006/excr.2002.5658)

Neubauer HA \& Pitson SM 2013 Roles, regulation and inhibitors of sphingosine kinase 2. FEBS Journal 280 5317-5336. (doi:10.1111/ febs.12314)

Ohotski J, Long JS, Orange C, Elsberger B, Mallon E, Doughty J, Pyne S, Pyne NJ \& Edwards J 2012 Expression of sphingosine 1-phosphate receptor 4 and sphingosine kinase 1 is associated with outcome in oestrogen receptor-negative breast cancer. British Journal of Cancer 106 1453-1459. (doi:10.1038/bjc.2012.98)

Pitson SM, Moretti PA, Zebol JR, Lynn HE, Xia P, Vadas MA \& Wattenberg BW 2003 Activation of sphingosine kinase 1 by ERK1/2-mediated phosphorylation. EMBO Journal 22 5491-5500. (doi:10.1093/emboj/cdg540)

Pitson SM, Xia P, Leclercq TM, Moretti PA, Zebol JR, Lynn HE, Wattenberg BW \& Vadas MA 2005 Phosphorylation-dependent translocation of sphingosine kinase to the plasma membrane drives its oncogenic signalling. Journal of Experimental Medicine 201 49-54. (doi:10.1084/jem.20040559)

Pyne S, Edwards J, Ohotski J \& Pyne NJ 2012 Sphingosine 1-phosphate receptors and sphingosine kinase 1 : novel biomarkers for clinical prognosis in breast, prostate, and hematological cancers. Frontiers in Oncology 2 168. (doi:10.3389/fonc.2012.00168)

Rolin J \& Maghazachi AA 2011 Effects of lysophospholipids on tumor microenvironment. Cancer Microenvironment 4 393-403. (doi:10.1007/ s12307-011-0088-1)

Rosen H \& Goetzl EJ 2005 Sphingosine 1-phosphate and its receptors: an autocrine and paracrine network. Nature Reviews. Immunology $\mathbf{5}$ 560-570. (doi:10.1038/nri1650)

Ruckhäberle E, Rody A, Engels K, Gaetje R, von Minckwitz G, Schiffmann S, Grösch S, Geisslinger G, Holtrich U, Karn T et al. 2008 Microarray 
analysis of altered sphingolipid metabolism reveals prognostic significance of sphingosine kinase 1 in breast cancer. Breast Cancer Research and Treatment 112 41-52. (doi:10.1007/s10549-007-9836-9)

Sanchez T, Thangada S, Wu MT, Kontos CD, Wu D, Wu H \& Hla T 2005 PTEN as an effector in the signaling of antimigratory $\mathrm{G}$ protein-coupled receptor. PNAS 102 4312-4317. (doi:10.1073/pnas.0409784102)

Sarkar S, Maceyka M, Hait NC, Paugh SW, Sankala H, Milstien S \& Spiegel S 2005 Sphingosine kinase 1 is required for migration, proliferation and survival of MCF-7 human breast cancer cells. FEBS Letters 579 5313-5317. (doi:10.1016/j.febslet.2005.08.055)

Shu X, Wu W, Mosteller RD \& Broek D 2002 Sphingosine kinase mediates vascular endothelial growth factor-induced activation of ras and mitogen-activated protein kinases. Molecular and Cellular Biology 22 7758-7768. (doi:10.1128/MCB.22.22.7758-7768.2002)

Sobue S, Hagiwara K, Banno Y, Tamiya-Koizumi K, Suzuki M, Takagi A, Kojima T, Asano H, Nozawa Y \& Murate T 2005 Transcription factor specificity protein 1 (Sp1) is the main regulator of nerve growth factor-induced sphingosine kinase 1 gene expression of the rat pheochromocytoma cell line, PC12. Journal of Neurochemistry 95 940-949. (doi:10.1111/j.1471-4159.2005.03399.x)

Spiegel S \& Milstien S 2007 Functions of the multifaceted family of sphingosine kinases and some close relatives. Journal of Biological Chemistry 282 2125-2129. (doi:10.1074/jbc.R600028200)

Spiegel S, Olivera A, Zhang H, Thompson EW, Su Y \& Berger A 1994 Sphingosine-1-phosphate, a novel second messenger involved in cell growth regulation and signal transduction, affects growth and invasiveness of human breast cancer cells. Breast Cancer Research and Treatment 31 337-348. (doi:10.1007/BF00666166)

Sukocheva OA, Wang L, Albanese N, Pitson SM, Vadas MA \& Xia P 2003 Sphingosine kinase transmits estrogen signaling in human breast cancer cells. Molecular Endocrinology 17 2002-2012. (doi:10.1210/me. 2003-0119)

Sukocheva O, Wadham C, Holmes A, Albanese N, Verrier E, Feng F, Bernal A, Derian CK, Ullrich A, Vadas MA et al. 2006 Estrogen transactivates EGFR via the sphingosine 1-phosphate receptor Edg-3: the role of sphingosine kinase-1. Journal of Cell Biology 173 301-310. (doi:10.1083/jcb.200506033)

Sukocheva O, Wang L, Verrier E, Vadas MA \& Xia P 2009 Restoring endocrine response in breast cancer cells by inhibition of the sphingosine kinase-1 signaling pathway. Endocrinology 150 4484-4492. (doi:10.1210/en.2009-0391)

Sukocheva O, Wadham C \& Xia P 2013 Estrogen defines the dynamics and destination of transactivated EGF receptor in breast cancer cells: role of S1P 3 receptor and Cdc42. Experimental Cell Research 319 455-465. (doi:10.1016/j.yexcr.2012.10.014)
Takabe K, Kim RH, Allegood JC, Mitra P, Ramachandran S, Nagahashi M, Harikumar KB, Hait NC, Milstien S \& Spiegel S 2010 Estradiol induces export of sphingosine 1-phosphate from breast cancer cells via ABCC1 and ABCG2. Journal of Biological Chemistry 285 10477-10486. (doi:10.1074/jbc.M109.064162)

Takuwa N, Du W, Kaneko E, Okamoto Y, Yoshioka K \& Takuwa Y 2011 Tumor-suppressive sphingosine-1-phosphate receptor-2 counteracting tumor-promoting sphingosine-1-phosphate receptor- 1 and sphingosine kinase 1-Jekyll Hidden behind Hyde. American Journal of Cancer Research 1 460-481.

Takuwa Y, Okamoto Y, Yoshioka K \& Takuwa N 2012 Sphingosine-1phosphate signaling in physiology and diseases. BioFactors 38 329-337. (doi:10.1002/biof.1030)

Thomas P \& Dong J 2006 Binding and activation of the seventransmembrane estrogen receptor GPR30 by environmental estrogens: a potential novel mechanism of endocrine disruption. Journal of Steroid Biochemistry and Molecular Biology 102 175-179. (doi:10.1016/j.jsbmb. 2006.09.017)

Vadas M, Xia P, McCaughan G \& Gamble J 2008 The role of sphingosine kinase 1 in cancer: oncogene or non-oncogene addiction? Biochimica et Biophysica Acta 1781 442-447. (doi:10.1016/j.bbalip.2008.06.007)

Watson C, Long JS, Orange C, Tannahill CL, Mallon E, McGlynn LM, Pyne S, Pyne NJ \& Edwards J 2010 High expression of sphingosine 1-phosphate receptors, $\mathrm{S}_{1} \mathrm{P}_{1}$ and $\mathrm{S}_{1} \mathrm{P}_{3}$, sphingosine kinase 1 , and extracellular signal-regulated kinase-1/2 is associated with development of tamoxifen resistance in estrogen receptor-positive breast cancer patients. American Journal of Pathology 177 2205-2215. (doi:10.2353/ajpath.2010.100220)

Xia P, Wang L, Gamble JR \& Vadas MA 1999 Activation of sphingosine kinase by tumor necrosis factor- $\alpha$ inhibits apoptosis in human endothelial cells. Journal of Biological Chemistry 274 34499-34505. (doi:10.1074/jbc.274.48.34499)

Xia P, Gamble JR, Wang L, Pitson SM, Moretti PA, Wattenberg BW, D'Andrea RJ \& Vadas MA 2000 An oncogenic role of sphingosine kinase. Current Biology 10 1527-1530. (doi:10.1016/S09609822(00)00834-4)

Young N \& Van Brocklyn JR 2007 Roles of sphingosine-1-phosphate (S1P) receptors in malignant behavior of glioma cells. Differential effects of ${\mathrm{S} 1 \mathrm{P}_{2}}_{2}$ on cell migration and invasiveness. Experimental Cell Research $\mathbf{3 1 3}$ 1615-1627. (doi:10.1016/j.yexcr.2007.02.009)

Zhang N, Qi Y, Wadham C, Wang L, Warren A, Di W \& Xia P 2010 FTY720 induces necrotic cell death and autophagy in ovarian cancer cells: a protective role of autophagy. Autophagy 6 1157-1167. (doi:10.4161/ auto.6.8.13614)

Received in final form 26 November 2013

Accepted 5 December 2013

Accepted Preprint published online 9 December 2013 http://joe.endocrinology-journals.org

DOI: $10.1530 / \mathrm{JOE}-13-0388$
(C) 2014 The authors Printed in Great Britain
Published by Bioscientifica Ltd 